\title{
Investigating the Impacts of Road Traffic Conditions and Driver's Characteristics on Automated Vehicle Takeover Time and Quality Using a Driving Simulator
}

\author{
Jaehyun Jason So $\mathbb{D}^{1}$, Sungho Park $\mathbb{D},{ }^{1}$ Jonghwa Kim $\mathbb{D}^{\mathbb{D}},{ }^{2}$ Jejin Park $\mathbb{D}^{3},{ }^{3}$ and Ilsoo Yun $\mathbb{D}^{1}$ \\ ${ }^{1}$ Department of Transportation System Engineering, Ajou University, Suwon, Republic of Korea \\ ${ }^{2}$ Korea Transportation Safety Authority, Gimcheon, Republic of Korea \\ ${ }^{3}$ Department of Civil Engineering, Chonnam National University, Gwangju, Republic of Korea
}

Correspondence should be addressed to Ilsoo Yun; ilsooyun@ajou.ac.kr

Received 9 July 2020; Revised 26 November 2020; Accepted 26 May 2021; Published 24 June 2021

Academic Editor: Mehdi Keyvan-Ekbatani

Copyright (c) 2021 Jaehyun Jason So et al. This is an open access article distributed under the Creative Commons Attribution License, which permits unrestricted use, distribution, and reproduction in any medium, provided the original work is properly cited.

\begin{abstract}
This study investigates the impacts of road traffic conditions and driver's characteristics on the takeover time in automated vehicles using a driving simulator. Automated vehicles are barely expected to maintain their fully automated driving capability at all times based on the current technologies, and the automated vehicle system transfers the vehicle control to a driver when the system can no longer be automatically operated. The takeover time is the duration from when the driver requested the vehicle control transition from the automated vehicle system to when the driver takes full control of the vehicle. This study assumes that the takeover time can vary according to the driver's characteristics and the road traffic conditions; the assessment is undertaken with various participants having different characteristics in various traffic volume conditions and road geometry conditions. To this end, $25 \mathrm{~km}$ of the northbound road section between Osan Interchange and Dongtan Junction on Gyeongbu Expressway in Korea is modeled in the driving simulator; the experiment participants are asked to drive the vehicle and take a response following a certain triggering event in the virtual driving environment. The results showed that the level of service and road curvature do not affect the takeover time itself, but they significantly affect the stabilization time, that is, a duration for a driver to become stable and recover to a normal state. Furthermore, age affected the takeover time, indicating that aged drivers are likely to slowly respond to a certain takeover situation, compared to the younger drivers. With these findings, this study emphasizes the importance of having effective countermeasures and driver interface to monitor drivers in the automated vehicle system; therefore, an early and effective alarm system to alert drivers for the vehicle takeover can secure enough time for stable recovery to manual driving and ultimately to achieve safety during the takeover.
\end{abstract}

\section{Introduction}

An automated vehicle (AV) can be defined as a vehicle that is capable of driving by its own sensing, decision, and control of a vehicle without the intervention of the driver. Many automotive manufacturers, Internet service providers, mobile carriers, and startup companies are developing AVs and the core technologies of AVs such as sensors, control algorithms, and roadside assistance systems, and some notable achievements have been already made and many AVs have been recently introduced to reality.
However, the AVs introduced recently perform in many different ways as the AVs are developed by different companies having different technologies and technological capabilities. Most of current AV technologies occasionally require control transition from $\mathrm{AV}$ to driver when the $\mathrm{AV}$ is unable to execute the driving tasks in response to surroundings or system failure. In other words, the current technologies are still staying in the driving automation level three, according to the Society of Automotive Engineers (SAE)'s six-step definition of driving automation. It is noted that SAE defined driving automation with six levels: no 
automation (level 0), driver assistance (level 1), partial automation (level 2), conditional automation (level 3), high automation (level 4), and full automation (level 5) [1]. In the levels 3 and 4, control transition from a vehicle to a driver, called "takeover," may occur; thus, the driver should be prepared for this takeover situation. However, unfortunately, it is not likely that the drivers may be prepared and perform relevant actions in response to the occasional takeover because it is hard to pay full attention to the surroundings during automated driving. Sluggish response of the driver during takeover can result in critical situations during automated driving. Therefore, the smooth takeover, which can be measured by the takeover time, is a critical factor to keep driving safe during automated driving.

While many factors can affect the safe takeover, drivers' characteristics and road traffic conditions are representative measures for affecting the takeover time. It is noted that the driver's characteristics include age, gender, driving experience, and average driving distance, and the road traffic conditions include congestion levels (i.e., level of service (LOS)) and road curvature. For example, a sophomoric driver may need a longer time for recognizing surrounding circumstances and taking relevant actions in response to sudden takeover situations, compared to a skilled driver. In addition, complexity may be higher when a driver is requested to take vehicle controls in a curved road section or a congested road section.

This study was initiated to determine whether road traffic conditions affect takeover time and quality. In addition, this study attempted to determine whether such effects differ by gender or age. To this end, this study measures the takeover times of experiment participants consisting of different demographic characteristics. It should be noted that the takeover time includes two different measures in this study, one is takeover time and the other is stabilization time. The takeover time is a time for the driver to take a control, and the stabilization time is a time for the driver to return to usual driving state and reach stability in driving. Experiments are performed using a driving simulator, which can model a realistic road traffic environment including road geometry and traffic controls. During the research process, curvature among road conditions and LOS among traffic conditions were selected as the most suitable variables for testing in a driving simulator. Note that the spatial scope of this study is set to motorways.

\section{Literature Review}

Significant study efforts have been made for the takeover of $\mathrm{AV}$ in recent years, as AV has been highlighted. Earlier studies on the AV control takeover have been made in three domains: takeover time; takeover alarming method to drivers; driver information types for takeover [2]. The literature on the takeover time measurements is reviewed in this section, as this study focuses on takeover time.

Hergeth et al. [3] investigated the effects of experiment orientation on the takeover time using a driving simulator. Four groups of subjects (i.e., experiment volunteers), including no orientation, oral explanation-based orientation, preliminary experiment practice-based orientation, and oral orientation and actual practice-based orientation, were prepared for the driving simulator-based experiments, depending on the level of preceding explanation about the experiment settings and objectives. The takeover time was measured twice for each participant, and it resulted in 2.5 seconds for both the actual practice setting group and the oral orientation and actual practice setting group; $3.0 \mathrm{sec}-$ onds for the oral experiment only setting group; 3.5 seconds for the no-orientation setting group. These results had similar values to the experiment performed. Gold et al. [4] examined the effects of traffic density on the takeover time. A total of 72 subjects were managed to drive a vehicle using a driving simulator, and the density of traffic was set to 0,10 , and 20 vehicles $/ \mathrm{km}$ for each scenario. The takeover time was 2.6, 3.4, and 3.5 seconds, respectively, for each density scenario, and this implies that the takeover could be more challenged in a higher density condition. Yoon et al. [5] measured the takeover time under different nondrivingrelated tasks (NDRTs) and different combinations of alarming methods, targeting four NDRT control groups (none, phone call, smartphone, and watching video) and seven control groups of different combinations of visual, auditory, and tactile modalities and alarming methods. A total of twenty subjects participated in the driving simulation experiment, and the takeover time was measured to be 2.31 seconds for the none-NDRT group; 2.29 seconds for the phone call group; 2.63 seconds for the smartphone group; and 2.10 seconds for the watching video group, showing that smartphone is the most critical to safety. Zhang et al. [6] examined mean takeover times from 129 trials with the SAE level 2 automation or higher. The authors performed a within-study analysis for investigating differences in mean takeover time for pairs of experimental conditions, a between-study analysis for investigating correlations between experimental conditions and mean takeover times, and a linear mixed-effects modeling to combine the effects of such two analysis methods, which indicated that a shorter mean takeover time is measured under a higher urgency of the situation. Besides, this study found that performing NDRT with a handheld device, performing a visual NDRT, a high level of automation (i.e., SAE level 3 and higher), and visualonly takeover request show longer mean takeover time. Eriksson and Stanton [7] examined existing research results on takeover and determined the takeover time to resume vehicle control from a highly AV in noncritical conditions through experiments. They compared the takeover times of 26 drivers with and without secondary tasks. As a result, they found out that drivers with secondary tasks showed larger variance and slower responses to requests to resume vehicle control.

Earlier studies have investigated takeover in terms of its duration by different orientation levels, traffic densities, and NDRT settings, and safety surrogate measures such as maximum acceleration and time to collision (TTC) were also estimated for assessing the performance of takeovers in terms of safety through some studies [3, 4]. While these studies measured the safety measured from the beginning of the takeover to the end of the takeover, none of the earlier 
studies assessed the safety after the actual takeover, which is also a critical moment until the driver comes to stability. As pointed in the Introduction section, the end of the takeover should be the point that the driver returns to the usual driving state and reach stability on driving. In this context, this study measures the takeover time with the actual takeover time and the stabilization time, which includes not only the moment before actual takeover but also the moment until the driver becomes stable on driving after the actual takeover. In addition, the earlier studies were limited in considering driver's characteristics and traffic state, including age, gender, driving experience, average driving distance, congestion levels (i.e., LOS), and road geometry, which could significantly affect the takeover behavior and duration. Therefore, this study investigates the impact of driver's characteristics (i.e., different driver settings) and road traffic state (i.e., LOS and geometry) on the takeover time taking into consideration the before and after takeover situations.

\section{Experiment Design}

3.1. Overview. This study measured the takeover time using a driving simulator called SCANER, which is capable of realizing the road and traffic conditions in a virtual environment. A total of 49 volunteers, including various ages and driving experiences, participated and were asked to drive the vehicle and take a response when needed in the virtual driving environment. Assuming that the takeover time can vary by the driver's characteristics and the road traffic conditions, the assessment was undertaken with various participants having different characteristics in the three traffic volume conditions and three road curvature conditions scenarios. Details in the evaluation scenarios and the simulation settings are described in the following section.

\subsection{Scenarios and Variables}

3.2.1. Drivers' Characteristics. The participants were recruited for the driving simulator-based experiments, and a total of 49 volunteers (i.e., 35 males and 14 females) finally participated in the experiments. Note that the selected experiment participants had no experience with driving simulators until this experiment while they drive on a daily basis. Table 1 shows the eight factors, including gender, age, driving experience, driving frequency, annual driving distance (previous year), academic background, occupation type, and annual income of the participants. For reference, because the recruitment of the participants was random, the human characteristics of the participants do not represent the human characteristics of the entire population in Korea.

3.2.2. Road Traffic Parameters. This study is set to consider the side influences such as traffic congestion (i.e., LOS) as the traffic state measure and road curvature as the road geometry measure. The traffic congestion is represented by a LOS, which is a 6-level measure of traffic congestion (i.e., from LOS A to LOS F) in the traffic engineering domain.
TABLE 1: Composition of experiment participants.

\begin{tabular}{|c|c|c|}
\hline Factors & Description & No. \\
\hline \multirow{2}{*}{ Gender } & Male & 35 \\
\hline & Female & 14 \\
\hline \multirow{5}{*}{ Age } & $20 \mathrm{~s}$ & 5 \\
\hline & $30 \mathrm{~s}$ & 12 \\
\hline & $40 \mathrm{~s}$ & 9 \\
\hline & $50 \mathrm{~s}$ & 12 \\
\hline & $60 \mathrm{~s}$ or older & 11 \\
\hline \multirow{4}{*}{ Driving experience } & Less than 10 years & 12 \\
\hline & 10 19 years & 15 \\
\hline & 20 29 years & 18 \\
\hline & 30 years or longer & 4 \\
\hline \multirow{4}{*}{ Driving frequency } & Almost every day & 33 \\
\hline & A few times per week & 11 \\
\hline & A few times per month & 3 \\
\hline & A few times per year & 2 \\
\hline \multirow{6}{*}{ Annual driving distance } & Less than $1,000 \mathrm{~km}$ & 7 \\
\hline & $1,000 \sim 4,999 \mathrm{~km}$ & 7 \\
\hline & $5,000 \sim 9,999 \mathrm{~km}$ & 10 \\
\hline & $10,000 \sim 19,999 \mathrm{~km}$ & 17 \\
\hline & $20,000 \sim 29,999 \mathrm{~km}$ & 5 \\
\hline & $30,000 \mathrm{~km}$ or longer & 3 \\
\hline \multirow{7}{*}{ Academic background } & Middle school graduate or lower & 0 \\
\hline & High school dropout & 0 \\
\hline & High school graduate & 7 \\
\hline & 2-year college dropout & 1 \\
\hline & 2-year college graduate & 8 \\
\hline & 4-year college dropout & 2 \\
\hline & 4-year college graduate or higher & 31 \\
\hline \multirow{5}{*}{ Occupation } & Student & 4 \\
\hline & Job-seeking & 5 \\
\hline & Retiree & 5 \\
\hline & Full-timer & 28 \\
\hline & Part-timer & 7 \\
\hline \multirow{7}{*}{ Annual income } & Lower than $10 \mathrm{~K}$ USD & 15 \\
\hline & $10 \mathrm{~K} \sim 20 \mathrm{~K}$ USD & 3 \\
\hline & $20 \mathrm{~K} \sim 30 \mathrm{~K}$ USD & 5 \\
\hline & $30 \mathrm{~K} \sim 40 \mathrm{~K}$ USD & 4 \\
\hline & $40 \mathrm{~K} \sim 50 \mathrm{~K}$ USD & 10 \\
\hline & $50 \mathrm{~K} \sim 60 \mathrm{~K}$ USD & 6 \\
\hline & $60 \mathrm{~K}$ USD or more & 6 \\
\hline
\end{tabular}

Among the six levels of traffic congestion, only LOS A, LOS $\mathrm{C}$, and LOS E are simulated and considered in this study, and the LOS C is set for a normal condition and the LOS A and E are set as the control groups. Note that LOS A indicates a free operation; LOS C implies a stable flow; LOS E corresponds to a capacity of the road. LOS F means a breakdown in vehicle flow that barely allows lane changes or any other traffic incidents; thus, this study does not include the LOS F in the traffic scenarios. To realize the traffic congestion levels in a driving simulator, hourly traffic volume and average speed were observed and captured from the northbound road section between Osan Interchange and Dongtan Junction on Gyeongbu Expressway in Korea. Therefore, $110 \mathrm{~km} / \mathrm{h}$, $85 \mathrm{~km} / \mathrm{h}$, and $75 \mathrm{~km} / \mathrm{h}$ as a speed measure and 4 -passenger car per km per lane (pcpkmpl), $12 \mathrm{pcpkmpl}$, and $23 \mathrm{pcpkmpl}$ as a traffic volume are set for the LOS A, LOS C, LOS E 
scenarios, respectively, based on the traffic volume guideline from Korea's Highway Capacity Manual (HCM) [8] and the observed speeds from the actual study section.

Out of various road geometric elements, curvature was selected as a variable. The road geometric elements of the mainline of highways that can affect driving include gradient, curvature, and superelevation, and superelevation was excluded since it is not constant due to the combination of curvature and geographical features. Gradient was also excluded in this study because changes in the gradient of highways are not significant, and it seems to be difficult to feel the gradient due to the characteristics of simulation. Since the mainline of highways was basically composed of straight lines, the control group was set to have a curvature that subjects would not feel uncomfortable while driving at $110 \mathrm{~km} / \mathrm{h}$, the speed limit of highways, and to have the minimum curvature that can guarantee safety while driving at the speed. The curvature was set not to include superelevation, and the minimum curvature was set to be 720 meters (m), referring to the minimum curvature of each design speed stated in the standards of road structures and facilities [9]. Before setting the curvature in which drivers would not feel uncomfortable while driving at the speed of $110 \mathrm{~km} / \mathrm{h}$, relevant documents and studies were reviewed, but no case identical to the condition was available. To set the curvature suitable for the condition, a questionnaire survey was conducted on experts on highway design and the curvature was set to 1,500 meters (m).

Finally, the evaluation scenarios considering the road traffic characteristics and the road geometric elements are set as shown in Table 2. The levels of service scenarios consist of three levels of service with $\mathrm{A}, \mathrm{C}$, and $\mathrm{E}$; the curvature scenarios also consist of three curvatures with straight line, 1,500 meters, and 720 meters. The subjects, participating in the driving simulation experiment, conducted a total of 9 times of experiments, consisting of three levels of curvature under three levels of LOS. Note that the orders of curvatures and LOSs were differently configured and they showed randomly to the subjects so that the subjects did not anticipate the next evaluation scenario.

\subsection{Experiment Method}

3.3.1. Simulation Settings. A driving simulator and its software, called SCANER, was used for implementing a virtual environment of the AV takeover, as shown in Figure 1 and Table 3. Using this SCANER, a total of $25 \mathrm{~km}$ was modeled with reference to the northbound road section between Osan Interchange and Dongtan Junction on Gyeongbu Expressway, and four lanes including one highoccupancy vehicle (HOV) lane were set for the vehicles to drive only on three lanes between the HOV lane and the shoulder lane. To minimize the side impact, the subject vehicle was not permitted for lane change but allowed for the other neighbor vehicles. Actual road geometry and traffic data collected on a weekday in February 2018 were used and applied. According to the lane designation policy of expressway in Korea, the left-most lane except HOV lane is for
TABle 2: Scenario settings.

\begin{tabular}{lcc}
\hline No. & Level of service & Curvature \\
\hline A-1 & & $720 \mathrm{~m}$ \\
A-2 & LOS A & Straight \\
A-3 & & $1,500 \mathrm{~m}$ \\
\hline C-1 & LOS C & Straight \\
C-2 & & $720 \mathrm{~m}$ \\
C-3 & & $1,500 \mathrm{~m}$ \\
\hline E-1 & LOS E & $1,500 \mathrm{~m}$ \\
E-2 & & Straight \\
E-3 & & $720 \mathrm{~m}$ \\
\hline
\end{tabular}

passing vehicles (i.e., overtaking), and the right-most lane is for trucks; thus, average cruising speed is higher in the leftmost lane and lower in the right-most lane. For a realistic traffic state, the vehicles driving on the left-most lane were set to drive $10 \mathrm{~km} / \mathrm{h}$ higher than the middle lane, and the vehicles driving on the right-most lane were set to drive $10 \mathrm{~km} / \mathrm{h}$ lower than the middle lane.

3.3.2. Triggering Takeover and Measurement. Triggering a takeover is the beginning point of the experiments. The takeover was requested to the driver when a random vehicle suddenly appears in front of the subject vehicle regardless of a distance within $100 \mathrm{~m}$ or being intentionally requested, assuming a system failure in case no vehicle appears in front of the subject vehicle. The participants were asked to start to manually drive the vehicle after taking over the control and staying in the lane at a constant speed. A single takeover event was set to consist of automated driving, takeover request, manual driving by participants, and recovering to automated driving sequentially. The takeover request was issued with auditory and visual alarms, and the alarms were set off simultaneously when the vehicle passed through a certain point and were set to be turned off either when the driver took over the control or when 30 seconds passed. For the drivers (i.e., experiment participants), 70 decibels of warning sound was used; a separate device for a visual alarm was placed on the dashboard; and the visual alarm device was set to show a takeover alarm and signs of driving status, including manual driving and automated driving. Although drivers must remain alert and keep their eyes forward in an automated driving mode according to the international recommendations and policies corresponding to the level 3 automated driving, this study assumed the situation that the drivers lose their attention to the forward circumstances. To realize this condition, an arrow task was assigned to the drivers as NDRT during the automated driving mode, as shown in Figure 1(d). It is noted that the arrow task consisted of multiple up, down, left, and right arrows and the drivers were asked to check the existence of a certain arrow as a game. Yoon et al. [5] confirmed that the type of NDRT affects the transfer of control rights. However, since the purpose of this study was not to check the effect of the types of NDRT on takeover time, the same NDRT was applied equally to all participants. For reference, the level of driver engagement in NDRT was not separately measured during 


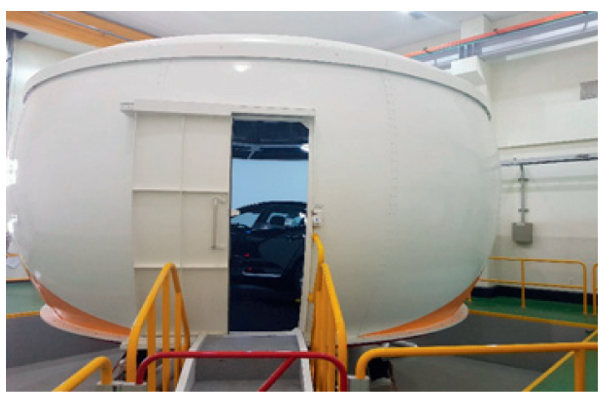

(a)

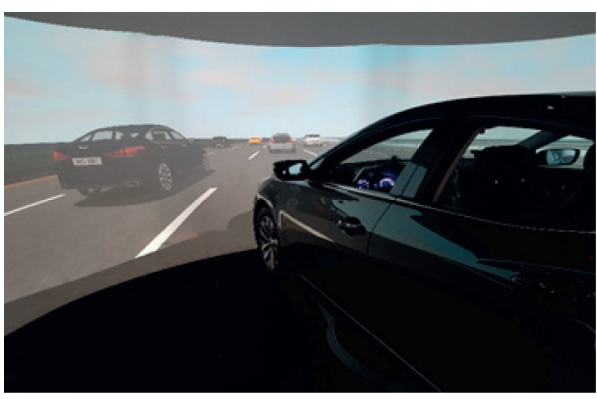

(b)

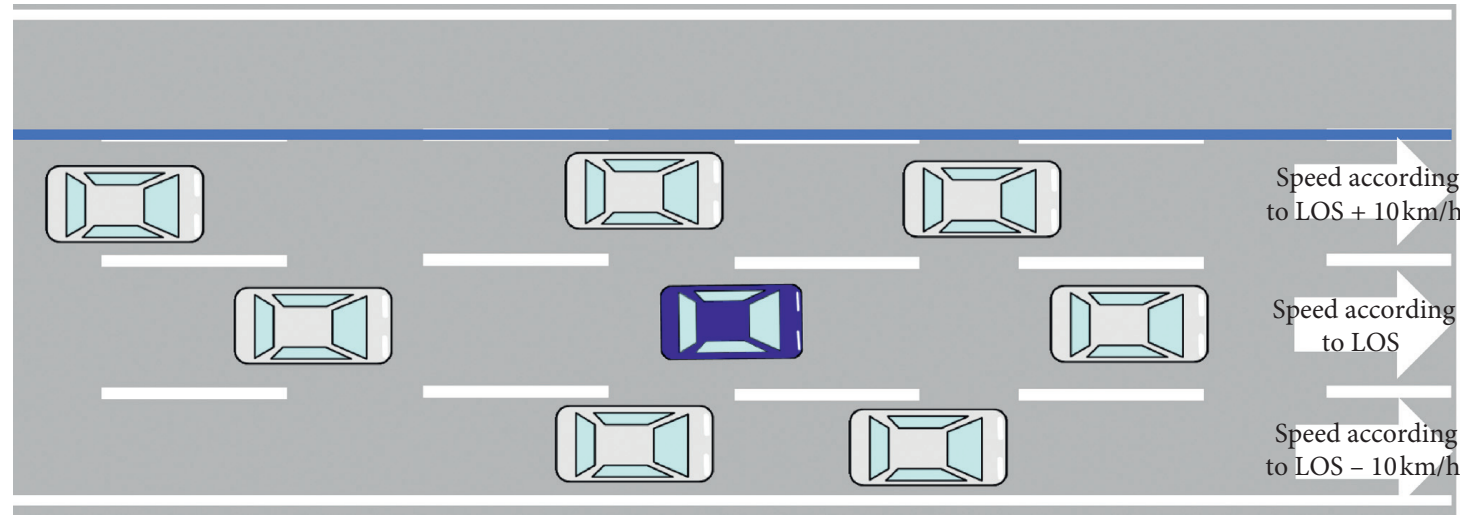

(c)

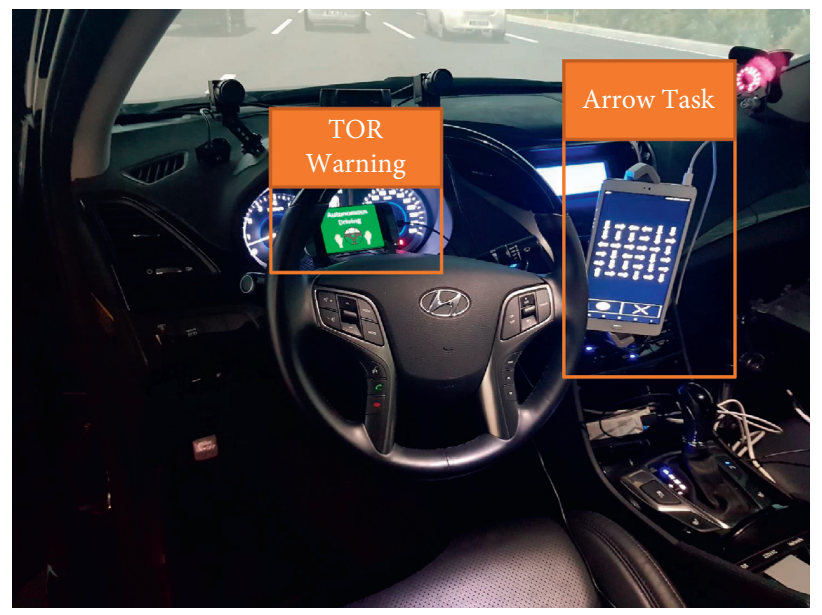

(d)

FIGURE 1: Exterior and interior settings of the driving simulator. (a) Exterior of the driving simulator. (b) Participant's view inside the driving simulator. (c) Lane configuration in SCANER. (d) Visual warning and NDRT devices.

TABLE 3: Specifications of driving simulator.

\begin{tabular}{lc}
\hline Component & Specification \\
\hline Motion platform & 6 degrees of freedom \\
Dome screen & Viewing angle: $360^{\circ} * 42^{\circ}$ \\
Driver monitoring system & 8 infrared cameras \\
Yaw table & $\pm 179^{\circ}$ \\
Video system & 8 projectors \\
Operation software & SCANeR STUDIO $1.1 \mathrm{v}$ \\
Cabin & HG grandeur \\
\hline
\end{tabular}

the experiment. However, the driver's concentration on the NDRT was continuously monitored through the cameras installed in the vehicle. If the driver does not respond to or does not concentrate on the NDRT, the driver is asked to focus on the NDRT.

Studies measuring the quality of takeover [10-12] used indicators such as TTC, steering wheel, and vehicle position in the lane. It was thought that TTC would be difficult to use when the distance from the vehicle in front is wide in a low 
traffic volume condition, such as LOS A. The vehicle position in the lane was excluded because the driver thought that it would be more difficult for the driver to determine his vehicle position than when driving the actual vehicle due to the characteristics of the simulator. Therefore, in this study, the steering wheel angle was used to measure the stabilization time. For example, based on the observation of the steering wheel of a driver, the movement angle of the steering wheel in a stable situation ranged from $-1^{\circ}$ to $1^{\circ}$, and the movement after takeover ranged approximately from $-2^{\circ}$ to $3^{\circ}$, which is greater than that in a stable situation. With the observation that the movement angle of the steering wheel shows a significant difference between such two different situations, this study uses the movement angle of the steering wheel as the indicator of takeover. Figure 2 shows the movement angel of the steering wheel in the observed moments (i.e., 20 seconds) during a stable situation and right after takeover, respectively. Note that these tests were performed on a straight road section.

However, the angle of the steering wheel is also challenged to distinguish the takeover at a curved road section because the steering wheel moves to drive along the curved section. Instead, a change in the angle of the steering wheel, measured with the interval of 0.1 seconds, was used as the indicator of takeover and its stabilization. While the change in the angle of the steering wheel was selected as an effective measure for distinguishing the takeover, the moves of steering angle can be different by drivers even if the drivers meet the same traffic situation requiring the same takeover and stabilization due to a difference among individuals. To overcome this individual difference and distinguish the moves of steering angle due to the takeover, the patterns of the steering angle's moves were recorded by each participant in advance of the actual tests so that the individual's pattern during the moves of steering angle is excluded in measuring the change in the angle of steering angle.

\subsubsection{Orientation for Experiment Participants.} Orientation (e.g., preceding explanation and practice driving) for experiment participants is a critical factor to affect the participants' behaviors, as shown through Hergeth et al. [3]'s study. However, this study made this orientation for all experiment participants at the same level; thus, this orientation does not affect the participants during experiments. The purpose of the orientation was to improve the participants' understanding of the experiment settings (i.e., mostly about the driving simulator and the traffic scene that appeared inside SCANER) and exclude any possible difficulties during the experiments. The orientation includes the experiment settings and procedure, the operation of $\mathrm{AV}$ mode inside the simulation, alarm and visual notice from the console, and the takeover process after the alarm and visual notice. The orientation was conducted until the participant understood the experiment sufficiently and took an average of 15 minutes. This orientation provided not only oral explanations but also test driving using SCANER. The test driving included one takeover request, and if the participant failed the takeover request, it was repeatedly executed. The test driving was performed for 5 to 10 minutes, depending on the degree to which the participant was adapted to the simulator. The overall experiment was conducted in the order of automated driving, takeover alarming and shifting to manual driving, and recovering to automated driving. However, it should be noted that motion sickness can be revealed due to discrepancies between the input to the visual organ and input to the vestibular organ [13]. Test driving took about 5-10 minutes, and experiment driving took about 5 minutes per scenario, taking a total of 45 minutes. Since the level of motion sickness increases in proportion to the time of experiencing virtual reality content, whenever the scenarios of LOS A, LOS C, and LOS E were over, the participant was given a break, and if the participant complained of motion sickness, the experiment was stopped immediately $[14,15]$.

3.3.4. Data Collection. A total of 441 data points collected from the experiment consisted of 9 times of 49 subjects (participants). Finally, six data points were identified as outliers; thus, a total of 435 data points were used for analysis in this study. Note that the six outliers were found because the participants did not properly manipulate the simulator due to a lack of understanding of the experiment. While the experiment is conducted 9 times for each participant, most of the outliers were found from the initial trials (i.e., 1st and 2nd trials).

The experiment data used in this study are extracted through repeated measurements of each participant; thus, the correlation among the repeated observations needs to be adjusted. A linear mixed model (LMM) is used to take care of the correlation and to estimate the effect of different experiment measurements, so the LMM allows the error terms and random effect and is relevant for nonindependent observations [16]. LMM is commonly used for such purposes, not only because of their simplicity but also because they may serve as approximations for models in other classes and are computationally easy to work with. LMM is extremely flexible and useful to model the covariance structure of dependent data and allow both unit-specific or population-averaged analyses [17]. Note that this study uses SPSS 18.0 for LMM [18].

$$
\mathrm{y}=\mathrm{X} \beta+Z \gamma+\varepsilon,
$$

where

$$
\begin{aligned}
& X=\text { design matrix for fixed effects, } \\
& Z=\text { design matrix for random effects, } \\
& \beta=\text { fixed effects parameters } \\
& \gamma=\text { random effects parameters } \\
& \mathcal{E}=\text { residual error. }
\end{aligned}
$$

\section{Analysis and Results}

4.1. Analysis on Takeover Time by Road Traffic Characteristics. As stated in the Experiment Design section, the takeover related times, including the duration until a driver takes 


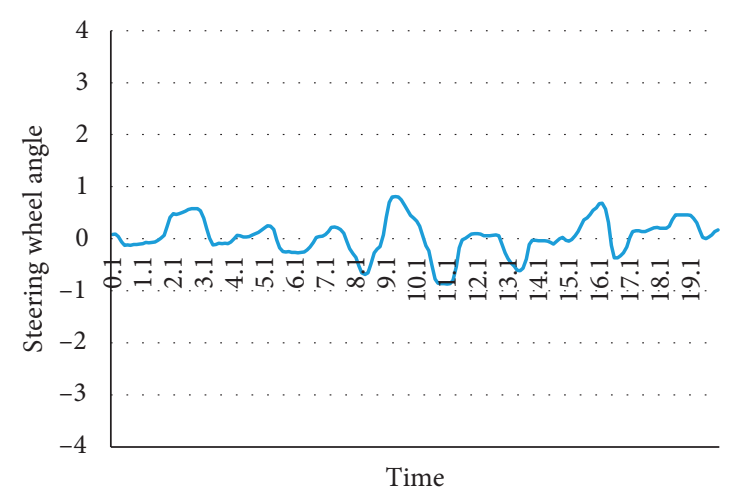

(a)

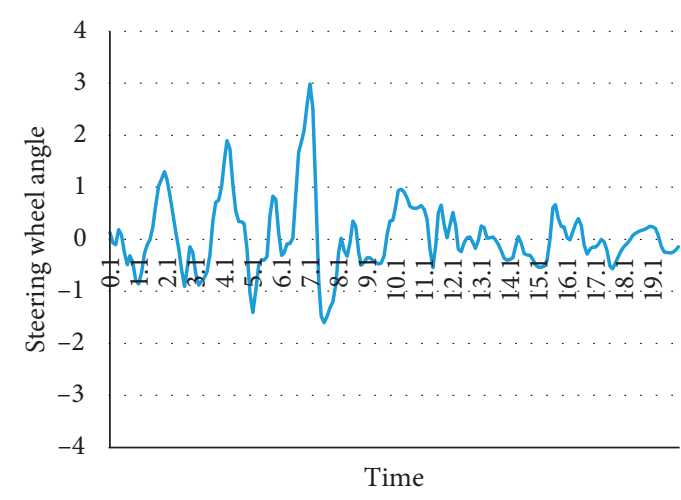

(b)

Figure 2: Observed movement of steering wheel. (a) Movement of steering wheel in a stable situation. (b) Movement of steering wheel after takeover.

vehicle control from the automated driving system (i.e., takeover time) and the duration until a driver becomes stable as usual from the moment of vehicle control takeover (i.e., stabilization time), are measured using a driving simulator. The experiment participants were asked to drive under different LOS and curvature situations in order to investigate the impact of road traffic characteristics on the takeover time. Note that the trajectory data were extracted from repeated trials using a driving simulator and the data extracted were analyzed using LMM. Firstly, the takeover time was examined by LOS and curvatures. Table 4 shows the results of the model constructed by LMM.

This study attempted to check the goodness of fit of LMM. However, it was difficult to find adequate goodness of fit measures. Many studies are being conducted to find the right goodness of fit measures [19-21]. For example, Harrison et al. [22] investigated the use of $R^{2}$ in LMM. According to Harrison et al. [22], many studies have been conducted to calculate $R^{2}$ in LMM, but a methodology that is clear enough to be used in general has not yet been developed. Therefore, in this study, AIC and BIC values, which are suggested in other studies using LMM, are presented in Table 5 [23]. In addition, the values of a null model, including only constants, are presented as a baseline with those of a full model in Table 5. This will help the readers to understand the improvement in the goodness of fit determined by the inclusion of the other variables.

Test statistics showed that the $p$ value of LOS and curvature is 0.821 and 0.792 , respectively, as shown in Table 6 . Accordingly, LOS and curvature did not significantly affect the drivers in terms of the takeover time at the $95 \%$ of confidence level.

For the LOS scenarios, the average takeover time was 2.30 seconds in LOS A; 2.23 seconds in LOS C; 2.32 seconds in LOS E. For the curvature scenarios, the average takeover time was 2.26 seconds in a straight line; 2.25 seconds in the $1,500 \mathrm{~m}$ radius curvature scenario; 2.34 seconds in the $720 \mathrm{~m}$ radius curvature scenario. Note that the standard deviation was 0.10 seconds for all scenarios. Table 7 shows the takeover times by the LOS and curvature scenarios.
Second, the stabilization time was also examined by LOS and curvature. Table 8 shows the results of the model constructed by LMM.

The information criteria of the derived model are shown in Table 9.

Test statistics showed that the $p$ value of LOS and curvature is 0.090 and $\leq 0.001$, respectively, as shown in Table 10. The results indicate that curvature significantly affected the drivers in terms of the stabilization time at the $95 \%$ of confidence level.

For the LOS scenarios, the average takeover time was 5.22 seconds ( 0.31 seconds of standard deviation) in LOS A; 4.32 seconds ( 0.31 seconds of standard deviation) in LOS C; and 5.07 seconds ( 0.31 seconds of standard deviation) in LOS E. For the curvature scenarios, the average takeover time was 3.59 seconds ( 0.29 seconds of standard deviation) in a straight line; 5.41 seconds ( 0.34 seconds of standard deviation) in the $1,500 \mathrm{~m}$ radius curvature scenario; 5.60 seconds (0.31 seconds of standard deviation) in the $720 \mathrm{~m}$ radius curvature scenario. Table 11 shows the measured stabilization time values by the LOS and curvature scenarios.

In addition, the pairwise comparison was performed in order to investigate which measure was more significant on the stabilization time among LOS and curvature. The results showed that the curvatures significantly affected the drivers than the LOS, and the impact of each curvature scenario (i.e., straight, $1,500 \mathrm{~m}$ radius and $720 \mathrm{~m}$ radius) was statistically significant at the $95 \%$ of confidence level, as shown in $\mathrm{Ta}$ ble 12 . The average takeover time of the $1,500 \mathrm{~m}$ radius and $720 \mathrm{~m}$ radius curvature scenarios was approximately 1.9 seconds longer than the straight line scenario, indicating that the drivers are likely to take approximately 1.9 seconds more at curved road sections until they become stable and recover to normal state, in comparison with the stabilization time at a straight section.

4.2. Analysis on Takeover Time by Driver's Characteristics. The takeover time, including takeover and stabilization, is measured using a driving simulator, and the results were 
TABLE 4: Estimated takeover time from LMM by LOS and curvature.

\begin{tabular}{|c|c|c|c|c|c|}
\hline Variables & & Estimate & Standard error & $t$-value & $p$ value \\
\hline Intercept & & 2.452 & 0.193 & 12.730 & $\leq 0.001$ \\
\hline \multirow{3}{*}{ Traffic congestion } & LOS A & -0.225 & 0.258 & -0.874 & 0.383 \\
\hline & LOS C & -0.389 & 0.256 & -1.523 & 0.129 \\
\hline & LOS E & 0.0 & 0.0 & - & - \\
\hline \multirow{3}{*}{ Curvature } & Straight & -0.221 & 0.257 & -0.858 & 0.392 \\
\hline & $1,500 \mathrm{~m}$ & 0.0 & 0.0 & - & - \\
\hline & $720 \mathrm{~m}$ & -0.167 & 0.258 & -0.645 & 0.520 \\
\hline \multirow{9}{*}{ Traffic congestion * curvature } & LOS A $*$ straight & 0.254 & 0.353 & 0.719 & 0.472 \\
\hline & LOS $A * 1,500 \mathrm{~m}$ & 0.0 & 0.0 & - & - \\
\hline & LOS A $* 720 \mathrm{~m}$ & 0.344 & 0.365 & 0.942 & 0.347 \\
\hline & LOS C $*$ straight & 0.460 & 0.362 & 1.269 & 0.205 \\
\hline & LOS C $* 1,500 \mathrm{~m}$ & 0.0 & 0.0 & - & - \\
\hline & LOS C $* 720 \mathrm{~m}$ & 0.439 & 0.356 & 1.233 & 0.218 \\
\hline & LOS E $*$ straight & 0.0 & 0.0 & - & - \\
\hline & LOS $\mathrm{E} * 1,500 \mathrm{~m}$ & 0.0 & 0.0 & - & - \\
\hline & LOS E $* 720 \mathrm{~m}$ & 0.0 & 0.0 & - & - \\
\hline
\end{tabular}

Note. Estimates of LOS E and 1,500 $\mathrm{m}$ are standard values of traffic congestion and curvature, so all corresponding values are marked as 0.0 .

TABLE 5: The information criteria output from the takeover time model by LOS and curvature.

\begin{tabular}{lcc}
\hline Information criteria & Null model & Full model \\
\hline-2 restricted log-likelihood & 1468.607 & 1448.254 \\
Akaike's information criterion (AIC) & 1474.607 & 1466.254 \\
Hurvich and Tsai's criterion (AICC) & 1474.652 & 1466.687 \\
Bozdogan's criterion (CAIC) & 1490.454 & 1511.744 \\
Schwarz's Bayesian criterion (BIC) & 1487.454 & 1502.744 \\
\hline
\end{tabular}

TABLE 6: Significance of road traffic measures on takeover time.

\begin{tabular}{lcc}
\hline Variables & F-value & $p$ value \\
\hline LOS & 0.198 & 0.821 \\
Curvature & 0.234 & 0.792 \\
\hline
\end{tabular}

${ }^{* *} p$ value is less than 0.05 , indicating that the difference is statistically significant at the $95 \%$ of confidence level.

TABLE 7: Takeover times by LOS and curvatures.

\begin{tabular}{lcccc}
\hline Variables & LOS A & LOS C & LOS E & Total \\
\hline Straight line & $2.26 \pm 0.17 \mathrm{sec}$ & $2.30 \pm 0.19 \mathrm{sec}$ & $2.23 \pm 0.17 \mathrm{sec}$ & $2.26 \pm 0.10 \mathrm{sec}$ \\
Curvature $1,500 \mathrm{~m}$ & $2.22 \pm 0.17 \mathrm{sec}$ & $2.06 \pm 0.17 \mathrm{sec}$ & $2.45 \pm 0.19 \mathrm{sec}$ & $2.25 \pm 0.10 \mathrm{sec}$ \\
Curvature $720 \mathrm{~m}$ & $2.40 \pm 0.19 \mathrm{sec}$ & $2.34 \pm 0.18 \mathrm{sec}$ & $2.29 \pm 0.17 \mathrm{sec}$ & $2.34 \pm 0.10 \mathrm{sec}$ \\
Total & $2.30 \pm 0.10 \mathrm{sec}$ & $2.23 \pm 0.10 \mathrm{sec}$ & $2.32 \pm 0.10 \mathrm{sec}$ & - \\
\hline
\end{tabular}

analyzed by driver's characteristics in order to investigate the driver's characteristics affecting the takeover maneuver. The driver's characteristics considered in this analysis are eight variables, including gender, age, driving experience, driving frequency, annual driving distance (previous year), academic background, occupation type, and annual income. Firstly, a collinearity test was performed to exclude the variables that have a strong relationship with the other variables [24]. A Spearman correlation coefficient was estimated among the variables, and Table 13 shows the entire correlation coefficients estimated. The results showed that a statistically significant correlation existed between age and driving experience $(r=0.722)$; driving frequency and annual driving distance $(r=0.583)$; occupation type and annual income $(r=0.444)$, at the $99 \%$ of confidence level. As a result of the collinearity test, it was confirmed that the correlation between age and driving experience was high, and the driving experience was excluded from the analysis items.

As a result of LMM analysis on takeover time according to driver characteristics, gender and age were found to be significant variables, and the results are shown in Table 14.

The information criteria of the derived model are shown in Table 15. 
TABLE 8: Estimated stabilization time from LMM by LOS and curvature.

\begin{tabular}{|c|c|c|c|c|c|}
\hline Variables & & Estimate & Standard error & $t$-value & $p$ value \\
\hline Intercept & & 5.540 & 0.537 & 10.316 & $\leq 0.001$ \\
\hline \multirow{3}{*}{ Traffic congestion } & LOS A & 1.023 & 0.811 & 1.262 & 0.208 \\
\hline & LOS C & -1.411 & 0.800 & -1.764 & 0.079 \\
\hline & LOS E & 0.0 & 0.0 & - & - \\
\hline \multirow{3}{*}{ Curvature } & Straight & -1.791 & 0.709 & -2.528 & 0.012 \\
\hline & $1,500 \mathrm{~m}$ & 0.0 & 0.0 & - & - \\
\hline & $720 \mathrm{~m}$ & 0.369 & 0.812 & 0.454 & 0.650 \\
\hline \multirow{9}{*}{ Traffic congestion * curvature } & LOS A $*$ straight & -1.285 & 1.041 & -1.234 & 0.218 \\
\hline & LOS $A * 1,500 \mathrm{~m}$ & 0.0 & 0.0 & - & - \\
\hline & LOS A * 720m & -1.325 & 1.145 & -1.157 & 0.248 \\
\hline & LOS C $*$ straight & 1.188 & 1.077 & 1.103 & 0.271 \\
\hline & LOS C $* 1,500 \mathrm{~m}$ & 0.0 & 0.0 & - & - \\
\hline & LOS C $* 720 \mathrm{~m}$ & 0.792 & 1.106 & 0.716 & 0.474 \\
\hline & LOS E $*$ straight & 0.0 & 0.0 & - & - \\
\hline & LOS $\mathrm{E} * 1,500 \mathrm{~m}$ & 0.0 & 0.0 & - & - \\
\hline & LOS E $* 720 \mathrm{~m}$ & 0.0 & 0.0 & - & - \\
\hline
\end{tabular}

Note. Estimates of LOS E and 1,500 $\mathrm{m}$ are standard values of traffic congestion and curvature, so all corresponding values are marked as 0.0 .

TABle 9: The information criteria output from stabilization time model by LOS and curvature.

\begin{tabular}{lcc}
\hline Information criteria & Null model & Full model \\
\hline-2 restricted log-likelihood & 3128.216 & 2379.610 \\
Akaike's information criterion (AIC) & 3134.216 & 2397.610 \\
Hurvich and Tsai's criterion (AICC) & 3134.261 & 2398.043 \\
Bozdogan's criterion (CAIC) & 3150.063 & 2443.100 \\
Schwarz's Bayesian criterion (BIC) & 3147.063 & 2434.100 \\
\hline
\end{tabular}

TABLE 10: Significance of road traffic measures on stabilization time.

\begin{tabular}{lcc}
\hline Variables & F-value & $p$ value \\
\hline LOS & 2.419 & 0.090 \\
Curvature & 14.000 & $\leq 0.001^{* *}$ \\
\hline
\end{tabular}

${ }^{* *} p$ value is less than 0.05 , indicating that the difference is statistically significant at the $95 \%$ of confidence level.

TABLE 11: Stabilization times by LOS and curvatures.

\begin{tabular}{lcccc}
\hline Variables & LOS A & LOS C & LOS E & Total \\
\hline Straight line & $3.49 \pm 0.46 \mathrm{sec}$ & $3.53 \pm 0.55 \mathrm{sec}$ & $3.75 \pm 0.46 \mathrm{sec}$ & $3.59 \pm 0.29 \mathrm{sec}$ \\
Curvature $1,500 \mathrm{~m}$ & $6.56 \pm 0.61 \mathrm{sec}$ & $4.13 \pm 0.59 \mathrm{sec}$ & $5.54 \pm 0.54 \mathrm{sec}$ & $5.41 \pm 0.34 \mathrm{sec}$ \\
Curvature $720 \mathrm{~m}$ & $5.61 \pm 0.53 \mathrm{sec}$ & $5.29 \pm 0.46 \mathrm{sec}$ & $5.91 \pm 0.61 \mathrm{sec}$ & $5.60 \pm 0.31 \mathrm{sec}$ \\
Total & $5.22 \pm 0.31 \mathrm{sec}$ & $4.32 \pm 0.31 \mathrm{sec}$ & $5.07 \pm 0.31 \mathrm{sec}$ & - \\
\hline
\end{tabular}

TABLe 12: Pairwise test results among curvatures on stabilization time.

\begin{tabular}{lccccc}
\hline Comparison btw. & & Mean difference & Standard deviation & Degree of freedom & Significance probability \\
\hline \multirow{2}{*}{ Straight line } & $1,500 \mathrm{~m}$ & -1.823 & 0.440 & 397.017 & $\leq 0.001^{* *}$ \\
& $720 \mathrm{~m}$ & -2.014 & 0.422 & 371.543 & $\leq 0.001^{* *}$ \\
\hline $1,500 \mathrm{~m}$ & $720 \mathrm{~m}$ & -0.191 & 0.457 & 344.352 & 1.000 \\
\hline
\end{tabular}

${ }^{* *} p$ value is less than 0.05 , indicating that the difference is statistically significant at the $95 \%$ of confidence level.

Test statistics showed that the $p$ value of gender and age is $\leq 0.001$ and $\leq 0.001$, respectively, as shown in Table 16 . The results indicate that gender and age significantly affect the takeover time at the $95 \%$ of confidence level.
The LMM analysis with the gender and age parameters indicates that the average takeover time was 2.04 seconds (0.06 seconds of standard deviation) for the male participants; 2.79 seconds ( 0.12 seconds of standard deviation) for 
TABLE 13: Correlation coefficients among variables.

\begin{tabular}{|c|c|c|c|c|c|c|c|c|}
\hline & Gender & Age & $\begin{array}{c}\text { Driving } \\
\text { experience }\end{array}$ & $\begin{array}{l}\text { Driving } \\
\text { frequency }\end{array}$ & $\begin{array}{c}\text { Annual driving } \\
\text { distance (previous } \\
\text { year) }\end{array}$ & $\begin{array}{c}\text { Academic } \\
\text { background }\end{array}$ & $\begin{array}{c}\text { Occupation } \\
\text { type }\end{array}$ & $\begin{array}{l}\text { Annual } \\
\text { income }\end{array}$ \\
\hline Gender & 1 & - & - & - & - & - & - & - \\
\hline Age & $0.216^{* *}$ & 1 & - & - & - & - & - & - \\
\hline Driving experience & -0.022 & $0.722^{* *}$ & 1 & - & - & - & - & - \\
\hline Driving frequency & 0.039 & -0.048 & $-0.146^{* *}$ & 1 & - & - & - & - \\
\hline $\begin{array}{l}\text { Annual driving } \\
\text { distance (previous } \\
\text { year) }\end{array}$ & $-0.336^{* *}$ & $-0.085^{*}$ & $0.118^{* *}$ & $-0.583^{* *}$ & 1 & - & - & - \\
\hline $\begin{array}{l}\text { Academic } \\
\text { background }\end{array}$ & $-0.241^{* *}$ & -0.049 & 0.052 & $0.088^{*}$ & 0.066 & 1 & - & - \\
\hline Occupation type & $0.255^{* *}$ & $0.224^{* *}$ & $0.110^{*}$ & -0.031 & -0.014 & $-0.208^{* *}$ & 1 & - \\
\hline Annual income & $-0.159^{* *}$ & $0.133^{* *}$ & $0.293^{* *}$ & $-0.194^{* *}$ & $0.268^{* *}$ & $-0.139^{* *}$ & $0.444^{* *}$ & 1 \\
\hline
\end{tabular}

${ }^{* *} p$ value is less than $0.01 ;{ }^{*} p$ value is less than 0.05 .

TABLE 14: Estimated takeover time from LMM by gender and age.

\begin{tabular}{|c|c|c|c|c|c|}
\hline Variables & & Estimate & Standard error & $t$-value & $p$ value \\
\hline Intercept & & 5.268 & 0.191 & 27.590 & $\leq 0.001$ \\
\hline \multirow{2}{*}{ Gender } & Male & -3.383 & 0.222 & -15.229 & $\leq 0.001$ \\
\hline & Female & 0.0 & 0.0 & - & - \\
\hline \multirow{5}{*}{ Age } & $20 \mathrm{~s}$ & -3.490 & 0.369 & -9.452 & $\leq 0.001$ \\
\hline & $30 \mathrm{~s}$ & -3.096 & 0.369 & -8.384 & $\leq 0.001$ \\
\hline & $40 \mathrm{~s}$ & -3.044 & 0.369 & -8.243 & $\leq 0.001$ \\
\hline & $50 \mathrm{~s}$ & -2.780 & 0.223 & -12.2455 & $\leq 0.001$ \\
\hline & $60 \mathrm{~s}$ or older & 0.0 & 0.0 & - & - \\
\hline \multirow{10}{*}{ Gender * age } & Male $* 20 \mathrm{~s}$ & 3.678 & 0.417 & 8.813 & $\leq 0.001$ \\
\hline & Male * $30 \mathrm{~s}$ & 3.002 & 0.398 & 7.545 & $\leq 0.001$ \\
\hline & Male $* 40 \mathrm{~s}$ & 3.329 & 0.403 & 8.262 & $\leq 0.001$ \\
\hline & Male $* 50 \mathrm{~s}$ & 3.194 & 0.296 & 10.785 & $\leq 0.001$ \\
\hline & Male $* 60 s$ or older & 0.0 & 0.0 & - & - \\
\hline & Female $* 20 \mathrm{~s}$ & 0.0 & 0.0 & - & - \\
\hline & Female $* 30 \mathrm{~s}$ & 0.0 & 0.0 & - & - \\
\hline & Female $* 40 \mathrm{~s}$ & 0.0 & 0.0 & - & - \\
\hline & Female $* 50 \mathrm{~s}$ & 0.0 & 0.0 & - & - \\
\hline & Female $* 60 \mathrm{~s}$ or older & 0.0 & 0.0 & - & - \\
\hline
\end{tabular}

Note. Estimates of females and $60 \mathrm{~s}$ or older are standard values of traffic congestion and curvature, so all corresponding values are marked as 0.0 .

TABLE 15: The information criteria output from the takeover time model by gender and age.

\begin{tabular}{lcc}
\hline Information criteria & Null model & Full model \\
\hline-2 restricted log-likelihood & 1468.607 & 1251.684 \\
Akaike's information criterion (AIC) & 1474.607 & 1269.684 \\
Hurvich and Tsai's criterion (AICC) & 1474.652 & 1270.118 \\
Bozdogan's criterion (CAIC) & 1490.454 & 1315.153 \\
Schwarz's Bayesian criterion (BIC) & 1487.454 & 1306.153 \\
\hline
\end{tabular}

the female participants; 1.93 seconds $(0.18$ seconds of standard deviation) for the $20 \mathrm{~s} ; 1.98$ seconds ( 0.17 seconds of standard deviation) for the $30 \mathrm{~s} ; 2.20$ seconds $(0.17 \mathrm{sec}-$ onds of standard deviation) for the $40 \mathrm{~s} ; 2.39$ seconds $(0.10$ seconds of standard deviation) for the $50 \mathrm{~s} ; 3.58$ seconds ( 0.11 seconds of standard deviation) for the $60 \mathrm{~s}$ or older. Table 17 shows the takeover time measured by gender and age.
In addition, a pairwise comparison was performed in order to investigate which measure was more significant on the takeover time among gender and age. Table 18 shows the pairwise test results among the gender and age parameters. The difference between male and female was 0.74 seconds, and the female participants took 0.74 seconds more in the takeover. This difference between genders was statistically significant (i.e., $p$ value is $\leq 0.001$ ) at the $95 \%$ of confidence 
TABLE 16: Significance of gender and age on takeover time.

\begin{tabular}{lcc}
\hline Variables & $F$-value & $p$ value \\
\hline Gender & 31.744 & $\leq 0.001^{* *}$ \\
Age & 29.015 & $\leq 0.001^{* *}$ \\
\hline
\end{tabular}

${ }^{* *} p$ value is less than 0.05 , indicating that the difference is statistically significant at the $95 \%$ of confidence level.

TABLE 17: Takeover time by gender and age.

\begin{tabular}{lcccccc}
\hline Variables & $20 \mathrm{~s}$ & $30 \mathrm{~s}$ & $40 \mathrm{~s}$ & $50 \mathrm{~s}$ & $60 \mathrm{~s}$ or older & Total \\
\hline Male & $2.07 \pm 0.16 \mathrm{sec}$ & $1.79 \pm 0.10 \mathrm{sec}$ & $2.17 \pm 0.12 \mathrm{sec}$ & $2.30 \pm 0.16 \mathrm{sec}$ & $1.88 \pm 0.11 \mathrm{sec}$ & $2.04 \pm 0.06 \mathrm{sec}$ \\
Female & $1.78 \pm 0.32 \mathrm{sec}$ & $2.17 \pm 0.32 \mathrm{sec}$ & $2.22 \pm 0.32 \mathrm{sec}$ & $2.49 \pm 0.12 \mathrm{sec}$ & $5.27 \pm 0.19 \mathrm{sec}$ & $2.79 \pm 0.12 \mathrm{sec}$ \\
Total & $1.93 \pm 0.18 \mathrm{sec}$ & $1.98 \pm 0.17 \mathrm{sec}$ & $2.20 \pm 0.17 \mathrm{sec}$ & $2.39 \pm 0.10 \mathrm{sec}$ & $3.58 \pm 0.11 \mathrm{sec}$ & - \\
\hline
\end{tabular}

TABle 18: Pairwise test results among genders and ages on takeover time.

\begin{tabular}{|c|c|c|c|c|c|c|}
\hline \multirow{2}{*}{$\frac{\text { Variables }}{\text { Gender }}$} & \multicolumn{2}{|c|}{ Type } & \multirow{2}{*}{$\frac{\text { Mean difference }}{-0.743}$} & \multirow{2}{*}{$\frac{\text { Standard deviation }}{0.132}$} & \multirow{2}{*}{$\frac{\text { Degree of freedom }}{308.709}$} & \multirow{2}{*}{$\frac{\text { Significance probability }}{\leq 0.001^{* *}}$} \\
\hline & Male & Female & & & & \\
\hline \multirow{10}{*}{ Age } & \multirow{4}{*}{$20 s$} & $30 \mathrm{~s}$ & -0.056 & 0.242 & 301.458 & 1.000 \\
\hline & & $40 \mathrm{~s}$ & -0.272 & 0.244 & 302.486 & 1.000 \\
\hline & & $50 \mathrm{~s}$ & -0.468 & 0.202 & 304.900 & 0.212 \\
\hline & & $60 \mathrm{~s}$ or older & -1.651 & 0.209 & 314.834 & $\leq 0.001^{* *}$ \\
\hline & \multirow{3}{*}{$30 \mathrm{~s}$} & $40 \mathrm{~s}$ & -0.216 & 0.236 & 302.559 & 1.000 \\
\hline & & $50 \mathrm{~s}$ & -0.412 & 0.192 & 305.270 & 0.326 \\
\hline & & $60 \mathrm{~s}$ or older & -1.595 & 0.199 & 316.152 & $\leq 0.001^{* *}$ \\
\hline & \multirow{2}{*}{$40 \mathrm{~s}$} & $50 \mathrm{~s}$ & -0.196 & 0.195 & 306.777 & 1.000 \\
\hline & & $60 \mathrm{~s}$ or older & -1.379 & 0.201 & 317.264 & $\leq 0.001^{* *}$ \\
\hline & $50 \mathrm{~s}$ & $60 \mathrm{~s}$ or older & -1.183 & 0.148 & 333.335 & $\leq 0.001^{* *}$ \\
\hline
\end{tabular}

${ }^{* *} p$ value is less than 0.05 , indicating that the difference is statistically significant at the $95 \%$ of confidence level.

level, indicating that the females are likely to take a longer takeover time in the vehicle control takeover. For the ages, $60 \mathrm{~s}$ (or older) took 1.65 seconds more than $20 \mathrm{~s}$ and 1.59 seconds more than $30 \mathrm{~s}$, and these differences were statistically significant among the other pairs of age groups. This implies that $60 \mathrm{~s}$ or older are likely to take approximately 1.6 seconds more than $20 \mathrm{~s}$ and $30 \mathrm{~s}$; thus, the takeover time would be critical for the aged drivers compared to the younger ages.

As a result of LMM analysis on stabilization time according to driver characteristics, all driver characteristics variables were found to be insignificant, so it was analyzed that there was no correlation between driver characteristics and stabilization time.

\section{Conclusions}

This study investigated the impacts of road traffic conditions and driver's characteristics on the AV control transition from the vehicle's automated system to a driver by measuring the takeover time and the stabilization time using a driving simulator. For investigating impacts of road traffic conditions and driver's characteristics on the AV control transition, three congestion levels (i.e., LOS A, LOS C, and LOS $\mathrm{E}$ ) and three curvatures (i.e., straight, 1,500 $\mathrm{m}$ radius, and $720 \mathrm{~m}$ radius) were considered for the evaluation scenarios, and the 49 experiment participants having different characteristics in gender, age, and driving experience and frequency were asked to drive a vehicle in such various scenario environments. The results showed that a longer stabilization time was needed to become stable as usual driving at a steep curvature compared to a straight line, while the congestion level did not significantly affect both the takeover time and the stabilization time. The average stabilization time of the $1,500 \mathrm{~m}$ radius and $720 \mathrm{~m}$ radius curvature scenarios was approximately 1.9 seconds longer than that of the straight line scenario, indicating that the drivers are likely to take approximately 1.9 seconds more at curved road sections until they become stable and recover to normal, in comparison with the stabilization time at a straight section. This means that the congestion level and curvature do not significantly affect the takeover itself, but the curvature would be a critical factor for a driver to become stable after takeover; thus, the automated system and its alarming scheme should be designed in consideration of various curvature environments. Furthermore, the results showed that ages and genders rather affected the vehicle takeover time while it did not affect the stabilization time. The average takeover time of elderly drivers (more than $60 \mathrm{~s}$ ) was significantly higher than the other age groups, while the average takeover time of females was slightly higher than that of males. In particular, the elderly driver needs an earlier 
and clear indicator or alarm to recognize the point of takeover so that they can prepare for the takeover and it goes smoothly and safely.

As such, this study would be a great reference for the AV system engineers to consider what kind of measures should be considered and how the alarming method of takeover should be designed in the AV system designing process, in response to various situations including road traffic conditions and driver's characteristics. Importantly, this study emphasizes not only the takeover time but also the stabilization time by investigating the takeover time in the separation of such two time durations. The study results indicated that the road curvature could affect a driver to become stable as usual driving, while the elderly drivers would take a longer time to have control over the vehicle.

Nevertheless, this study still needs to be enhanced by hiring a statistically significant number of subjects, additional traffic scenarios including incidents, and additional driver's characteristics including human factors. In addition, this study would like to emphasize the importance of pretraining and orientation to the experiment participants in order to prevent any mistakes in manipulating a simulator or in responding to the trigger of takeover.

\section{Data Availability}

This study was supported by the Ministry of Land, Infrastructure and Transport's Transportation Logistics Research Project Funding (Task Nos. 20TLRP-B131486- 04 and 21TLRP-B147674-04).

\section{Conflicts of Interest}

The authors declare that they have no conflicts of interest.

\section{Acknowledgments}

This study was supported by the Ministry of Land, Infrastructure and Transport Transportation Logistics Research Project Funding (Task Nos.: 20TLRP-B131486- 04 and 21TLRP-B147674-04).

\section{References}

[1] SAE, "J3016- taxonomy and definitions for terms related to on-road motor vehicle automated driving systems," $S A E$ Standard, vol. 4, pp. 593-598, 2014.

[2] N. Kim, M. Yang, J. Lee, and J. Kim, "A study on the effect of information types on Drivers in Takeover period of automated vehicles," Journal of Digital Contents Society, vol. 19, no. 1, pp. 113-122, 2018.

[3] S. Hergeth, L. Lorenz, and J. F. Krems, "Prior familiarization with takeover requests affects drivers' takeover performance and automation trust," Human Factors, vol. 59, no. 3, pp. 457-470, 2017.

[4] C. Gold, M. Körber, D. Lechner, and K. Bengler, "Taking over control from highly automated vehicles in complex traffic situations," Human Factors: The Journal of the Human Factors and Ergonomics Society, vol. 58, no. 4, pp. 642-652, 2016.

[5] S. H. Yoon, Y. W. Kim, and Y. G. Ji, "The effects of takeover request modalities on highly automated car control transitions," Accident Analysis and Prevention, vol. 123, pp. 150-158, 2019.

[6] B. Zhang, J. de Winter, S. Varotto, R. Happee, and M. Martens, "Determinants of take-over time from automated driving: a meta-analysis of 129 studies," Transportation Research Part F: Traffic Psychology and Behaviour, vol. 64, pp. 285-307, 2019.

[7] A. Eriksson and N. A. Stanton, "Takeover time in highly automated vehicles: noncritical transitions to and from manual control," Human Factors: The Journal of the Human Factors and Ergonomics Society, vol. 59, no. 4, pp. 689-705, 2017.

[8] MOLIT, Korea's Highway Capacity Manual, MOLIT, Sejong, Korea, 2013.

[9] S. Lee, Y. Huh, Y. Nam, and D. Choi, "Introduction to the Korea's road engineering structure and facility design manual," Korean Society of Road Engineers, vol. 11, no. 2, pp. 48-53, 2009.

[10] N. Du, J. Kim, F. Zhou et al., "Evaluating effects of cognitive load, takeover request lead time, and traffic density on drivers' takeover performance in conditionally automated driving," in Proceedings of 12th International Conference on Automotive User Interfaces and Interactive Vehicular Applications, pp. 66-73, New York, NY, USA, September 2020.

[11] F. M. Favarò, P. Seewald, M. Scholtes, and S. Eurich, "Quality of control takeover following disengagements in semi-automated vehicles," Transportation Research Part F: Traffic Psychology and Behaviour, vol. 64, pp. 196-212, 2019.

[12] F. Naujoks, C. Purucker, K. Wiedemann, and C. Marberger, "Noncritical state transitions during conditionally automated driving on German freeways: effects of non-driving related tasks on takeover time and takeover quality," Human Factors, vol. 61, no. 4, pp. 596-613, 2019.

[13] F. Bonato, A. Bubka, and S. Palmisano, "Combined pitch and roll and cybersickness in a virtual environment," Aviation, Space, and Environmental Medicine, vol. 80, no. 11, pp. 941945, 2009.

[14] T. Kiryu and R. H. Y. So, "Sensation of presence and cybersickness in applications of virtual reality for advanced rehabilitation," Journal of NeuroEngineering and Rehabilitation, vol. 4, 2007.

[15] J. J. LaViola, "A discussion of cybersickness in virtual environments," ACM SIGCHI Bulletin, vol. 32, no. 1, pp. 47-56, 2000.

[16] G. Yannis, E. Papadimitriou, and K. Folla, "Effect of GDP changes on road traffic fatalities," Safety Science, vol. 63, pp. 42-49, 2014.

[17] J. M. Singer, F. M. M. Rocha, and J. S. Nobre, "Graphical tools for detecting departures from linear mixed model assumptions and aome remedial measures," International Statistical Review, vol. 85, no. 2, pp. 290-324, 2017.

[18] IBM, IBM SPSS Modeler 18.0 Manuals, IBM, Armonk, NY, USA, 2018, https://www.ibm.com/support/pages/spssmodeler-180-documentation\#en.

[19] P. C. Johnson, "Extension of Nakagawa \& Schielzeth's R2GLMM to random slopes models," Methods in Ecology and Evolution, vol. 5, no. 9, pp. 944-946, 2014.

[20] S. Nakagawa and H. Schielzeth, "A general and simple method for obtaining R2 from generalized linear mixed-effects models," Methods in Ecology and Evolution, vol. 4, no. 2, pp. 133-142, 2013.

[21] S. Nakagawa, P. C. Johnson, and H. Schielzeth, "The coefficient of determination R 2 and intra-class correlation coefficient from generalized linear mixed-effects models revisited 
and expanded," Journal of the Royal Society Interface, vol. 14, no. 134, Article ID 2017021, 2017.

[22] X. A. Harrison, L. Donaldson, M. E. Correa-Cano et al., “A brief introduction to mixed effects modelling and multimodel inference in ecology," PeerJ, vol. 6, p. e4794, 2018.

[23] J. R. Dillman, S. F. Dehkordy, E. A. Smith et al., "Defining the ultrasound longitudinal natural history of newly diagnosed pediatric small bowel Crohn disease treated with infliximab and infliximab-azathioprine combination therapy," Pediatric Radiology, vol. 47, no. 8, pp. 924-934, 2017.

[24] L. Myers and M. Sirois, "Spearman correlation coefficients, differences between," Encyclopedia of Statistical Sciences, vol. 12, 2004. 